\title{
Relative abundance of parasitoids reared during field exposure of sentinel larvae of the leafminers Liriomyza trifolii (Burgess), L. sativae Blanchard, and Chromatomyia horticola (Goureau) (Diptera: Agromyzidae)
}

\author{
Kae Amano, Ai Suzuki, Hajime Hiromori and Tsutomu Saito* \\ Faculty of Agriculture, Shizuoka University; Suruga, Shizuoka 422-8529, Japan \\ (Received 13 November 2007; Accepted 1 August 2008)
}

\begin{abstract}
In order to examine the relative abundance of indigenous parasitoids against three leafminer species, Liriomyza trifolii, L. sativae and Chromatomyia horticola, kidney bean plants infested with larvae of each species were exposed in vegetable gardens or grassland to different seasonal conditions (spring, summer and fall). Abundant parasitoid species were Chrysocharis pentheus, Diglyphus isaea and D. minoeus in spring or fall, and Neochrysocharis formosa, D. albiscapus and D. pusztensis in summer. Also, abundant parasitoid species varied among the different field conditions; however, within the same season and field the dominant parasitoid species were similar in all three leafminer species tested. Our findings indicate that the dominant parasitoid species did not exhibit any strong preference in the field between the three host species, namely L. trifolii, L. sativae or C. horticola.
\end{abstract}

Key words: Leafminer; Liriomyza trifolii; Liriomyza sativae; Chromatomyia horticola; parasitoid

\section{INTRODUCTION}

The agromyzid leafminers Liriomyza trifolii (Burgess) and L. sativae Blanchard are serious pests of vegetables and ornamental crops around the world. In Japan, they were first recorded in 1990 and 1999, respectively (Saito, 1993; Iwasaki et al., 2000). In addition, an indigenous leafminer, Chromatomyia horticola (Goureau), has been an economically important pest of garden pea, lettuce and Japanese radish since the late 1990s (Saito, 2004). All three leafminers have developed high levels of resistance to a range of chemical insecticides (e.g. Parrella and Keil, 1984; Saito et al., 1992; Saito, 2004; Ohta et al., 2005; Tokumaru et al., 2005), but insecticides do eliminate local parasitoids, leading to pest resurgence, suggesting that parasitoids may be important natural enemies of leafminers under insecticide-free conditions (e.g. Oatman and Kennedy, 1976; Schuster and Price, 1985; Saito et al., 1996; Saito, 2004). These findings clearly demonstrate that strategies such as conservation and enhancement of local parasitoids are essential for successful integrated leafminer management.

In Japan, more than 30 species of parasitoids have been recorded from agromyzid leafminers (Kamijo, 1978; Takada and Kamijo, 1979; Konishi, 1998). Most parasitoids of agromyzid leafminers are thought to be polyphagous, but mechanisms for host preference and selection by leafminer parasitoids are poorly understood (Murphy and LaSalle, 1999). The objective of this study was to evaluate the relative abundance of indigenous parasitoids on L. trifolii, L. sativae and C. horticola by exposing kidney bean plants infested with sentinel leafminer larvae to naturally occurring parasitoid species under different field and seasonal conditions. The results are discussed in terms of host, habitat and seasonal preferences of the commonly found leafminer parasitoids.

\section{MATERIALS AND METHODS}

Leafminer laboratory cultures. A laboratory culture of $L$. trifolii was established from a popula-

* To whom correspondence should be addressed at: E-mail: saitoh@agr.shizuoka.ac.jp DOI: $10.1303 / \mathrm{aez} .2008 .625$ 
tion collected in Hamamatsu, Shizuoka, Japan in April 1991, a culture of L. sativae was established from a population collected in Iwata, Shizuoka, Japan in June 2004, and a C. horticola culture was established from a population collected in Iwata, Shizuoka, Japan in April 2005. The cultures were maintained on the primary leaves of kidney bean (Phaseolus vulgaris L.). Pots of kidney bean plants were prepared for exposure experiments as follows; about 100 adults of each leafminer species were released into plastic cages $(38 \times 40 \times 30 \mathrm{~cm})$ containing 20 seedlings of kidney bean bearing primary leaves, with one seedling per pot $(9 \mathrm{~cm}$ diameter). After incubation for one day at $25 \pm 1^{\circ} \mathrm{C}$ and 16L:8D photoperiod, the kidney bean plants were removed and kept in a separate cage for three days under the same conditions described until eggs hatched. Kidney beans infested with approximately 30-50 individuals of 1st instar leafminer larvae per primary leaf were used in field exposure experiments.

Exposure experiments. Experiments were carried out in spring (May), summer (August to September) and fall (November) in 2005. Three experimental fields, two vegetable gardens for private household use and an area of grassland, were established in and around Shizuoka University, located in Ohya, Shizuoka, Japan. In Garden A $(30 \times 50 \mathrm{~m})$, vegetables such as garden pea (Pisum sativum L.) were grown. In Garden B $(40 \times 40 \mathrm{~m})$, vegetables such as radish (Raphanus sativus L.), tomato (Lycopersicon esculentum Mill.) and komatsuna (Brassica rapa L. "Nothovar") were grown. In Gardens $\mathrm{A}$ and $\mathrm{B}$, there were pre-existing infestations of C. horticola and L. sativae, respectively, but no insecticides were used for leafminer control. The grassland area $(50 \times 50 \mathrm{~m})$ contained weeds, mostly Compositae and Gramineae such as tall goldenrod (Solidago altissima L.) and southern crabgrass (Digitaria ciliaris (Retz.) Koel.). No leafminer infestations were observed in the grassland area. The spring survey was carried out in Garden A and grassland, and the summer and fall surveys in Garden B and grassland.

For each leafminer species, five pots of infested kidney beans were placed in trays $(35 \times 46 \times 5 \mathrm{~cm})$, with one pot per tray. For experimental exposure, 15 trays (5 per leafminer species) were placed in each of the experimental areas. To catch Liriomyza pupae, filter paper was placed on the soil surface of each pot and trays were covered with gauze (mesh $0.2 \mathrm{~mm}$ ). The kidney bean plants were exposed for one week in the spring and summer surveys, and for two weeks in the fall survey. After each exposure, leaves containing parasitoids and leafminers were removed and Liriomyza leafminer pupae in the trays were collected. The insect samples were placed on dry paper towels and incubated in plastic cups ( $12 \mathrm{~cm}$ diameter, $10 \mathrm{~cm}$ height) with mesh lids and maintained at $25 \pm 1{ }^{\circ} \mathrm{C}$ and $16 \mathrm{~L}: 8 \mathrm{D}$ photoperiod. After one month, emerged parasitoid and leafminer adults were counted, and parasitoids were identified using taxonomic keys by Konishi (1998).

\section{RESULTS}

Results of the spring survey are shown in Table 1. In Garden A, six parasitoid species were identified. Of these, Chrysocharis pentheus (Walker) was the dominant parasitoid from all three leafminer species, and Diglyphus isaea (Walker) and Neochrysocharis formosa (Westwood) were commonly found in all leafminer species. In grassland, eight parasitoid species were identified. $N$. formosa had the highest abundance of all leafminer species, while the number of $D$. isaea was high from $L$. trifolii and C. horticola, and Opius sp. showed high abundance in L. sativae. Leafminer species other than the species tested were collected from almost all of the samples, because leafminer species naturally occurring in the field study area appeared to lay eggs on the exposed kidney beans.

Results of the summer survey are shown in Table 2. In Garden B, nine parasitoid species were obtained. Of these, D. pusztensis (Erdös \& Novicky) was the most abundant in L. trifolii and C. horticola, while $N$. formosa was the most abundant in L. sativae, and high numbers were reared from L. trifolii and C. horticola. Also, many adults of $L$. sativae were collected from trays with samples of L. trifolii and C. horticola exposed in Garden B. In grassland, six parasitoid species were obtained and the abundance of D. albiscapus Erdös and $N$. formosa was high in all three leafminer species.

Results of the fall survey are shown in Table 3. D. isaea and D. minoeus (Walker) were the two dominant parasitoids of all three leafminer species in Garden B and grassland, respectively. However, 
Table 1. Number and percent composition (in parenthesis) of parasitoids and leafminers obtained in the spring survey

\begin{tabular}{|c|c|c|c|c|c|c|}
\hline \multirow{2}{*}{ Parasitoid and leafminer } & \multicolumn{3}{|c|}{ Garden A } & \multicolumn{3}{|c|}{ Grassland } \\
\hline & L. trifolii & L. sativae & C. horticola & L. trifolii & L. sativae & C. horticola \\
\hline \multicolumn{7}{|l|}{ Parasitoid } \\
\hline \multicolumn{7}{|l|}{ Braconidae } \\
\hline Dacnusa sasakawai Takada & $3(0.5)$ & & & & & \\
\hline Opius sp. & & & & $3(0.5)$ & $42(32.1)^{\dagger}$ & $12(14.5)$ \\
\hline \multicolumn{7}{|l|}{ Eulophidae } \\
\hline Chrysocharis pentheus (Walker) & $245(42.5)^{\ddagger}$ & $202(48.0)^{*}$ & $31(44.9)^{\ddagger}$ & $27(4.8)$ & $12(9.2)$ & $3(3.6)$ \\
\hline Diglyphus albiscapus Erdös & $5(0.9)$ & $1(0.2)$ & $2(2.9)$ & $37(6.6)$ & $1(0.8)$ & $1(1.2)$ \\
\hline Diglyphus isaea (Walker) & $162(28.1)^{\dagger}$ & $73(17.3)$ & $17(24.6)^{\dagger}$ & $181(32.1)^{\dagger}$ & $10(7.6)$ & $13(15.7)^{\dagger}$ \\
\hline Hemiptarsenus varicornis (Girault) & & & & $10(1.8)$ & & \\
\hline Neochrysocharis formosa (Westwood) & $131(22.7)$ & $117(27.8)^{\dagger}$ & $7(10.2)$ & $265(46.8)^{\ddagger}$ & $65(49.6)^{\ddagger}$ & $41(49.4)^{\ddagger}$ \\
\hline Neochrysocharis sp. & $31(5.4)$ & $25(5.9)$ & $12(17.4)$ & $38(6.7)$ & $1(0.8)$ & $10(12.0)$ \\
\hline Pnigalio katonis (Ishii) & & & & $2(0.4)$ & & $3(3.6)$ \\
\hline Unknown species & & $3(0.7)$ & & $1(0.2)$ & & \\
\hline Total number & 577 & 421 & 69 & 564 & 131 & 83 \\
\hline \multicolumn{7}{|l|}{ Leafminer } \\
\hline Liriomyza trifolii (Burgess) & 14 & & & 37 & 46 & 39 \\
\hline Liriomyza sativae Blanchard & & 23 & 1 & 17 & 136 & 26 \\
\hline Chromatomyia horticola (Goureau) & & 1 & 6 & & & 31 \\
\hline Total number & 14 & 24 & 7 & 54 & 182 & 96 \\
\hline
\end{tabular}

For each leafminer species, parasitoid species causing the highest $(\ddagger)$ and second highest $(\dagger)$ percent composition are indicated.

Table 2. Number and percent composition (in parenthesis) of parasitoids and leafminers obtained in the summer survey

\begin{tabular}{|c|c|c|c|c|c|c|}
\hline \multirow{2}{*}{ Parasitoid and leafminer } & \multicolumn{3}{|c|}{ Garden B } & \multicolumn{3}{|c|}{ Grassland } \\
\hline & L. trifolii & L. sativae & C. horticola & L. trifolii & L. sativae & C. horticola \\
\hline \multicolumn{7}{|l|}{ Parasitoid } \\
\hline \multicolumn{7}{|l|}{ Braconidae } \\
\hline Dacnusa sasakawai Takada & $3(4.5)$ & & & & & \\
\hline Opius sp. & $1(1.5)$ & & & $7(12.7)$ & & $1(1.8)$ \\
\hline \multicolumn{7}{|l|}{ Eulophidae } \\
\hline Asecodes delucchii (Boucek) & & & & $1(1.8)$ & $1(1.9)$ & $1(1.8)$ \\
\hline Chrysocharis pentheus (Walker) & $4(6.0)$ & $6(18.8)^{\dagger}$ & $17(14.5)$ & $5(9.1)$ & & \\
\hline Diglyphus albiscapus Erdös & $14(20.9)^{\dagger}$ & & $7(6.0)$ & $26(47.3)^{*}$ & $30(56.6)^{\ddagger}$ & $18(32.1)^{\dagger}$ \\
\hline Diglyphus isaea (Walker) & $2(3.0)$ & & & & & \\
\hline Diglyphus pusztensis (Erdös \& Novicky) & $21(31.3)^{\ddagger}$ & $3(9.4)$ & $37(31.6)^{\ddagger}$ & & & \\
\hline Hemiptarsenus varicornis (Girault) & $4(6.0)$ & $1(3.1)$ & $1(0.9)$ & & & \\
\hline Neochrysocharis formosa (Westwood) & $14(20.9)^{\dagger}$ & $18(56.3)^{\ddagger}$ & $29(24.8)^{\dagger}$ & $12(21.8)^{\dagger}$ & $21(39.6)^{\dagger}$ & $36(64.3)^{\ddagger}$ \\
\hline Neochrysocharis sp. & $4(6.0)$ & $4(12.5)$ & $26(22.2)$ & $4(7.3)$ & $1(1.9)$ & \\
\hline Total number & 67 & 32 & 117 & 55 & 53 & 56 \\
\hline \multicolumn{7}{|l|}{ Leafminer } \\
\hline Liriomyza trifolii (Burgess) & 25 & & & 51 & 2 & \\
\hline Liriomyza sativae Blanchard & 223 & 569 & 541 & & 12 & \\
\hline Chromatomyia horticola (Goureau) & & & 4 & & & 7 \\
\hline Total number & 248 & 569 & 545 & 51 & 14 & 7 \\
\hline
\end{tabular}

For each leafminer species, parasitoid species causing the highest $(\ddagger)$ and second highest $(\dagger)$ percent composition are indicated. 
Table 3. Number and percent composition (in parenthesis) of parasitoids and leafminers obtained in the fall survey

\begin{tabular}{|c|c|c|c|c|c|c|}
\hline \multirow{2}{*}{ Parasitoid and leafminer } & \multicolumn{3}{|c|}{ Garden B } & \multicolumn{3}{|c|}{ Grassland } \\
\hline & L. trifolii & L. sativae & C. horticola & L. trifolii & L. sativae & C. horticola \\
\hline \multicolumn{7}{|l|}{ Parasitoid } \\
\hline \multicolumn{7}{|l|}{ Braconidae } \\
\hline Opius sp. & & & & $6(23.1)^{\dagger}$ & & $8(24.2)^{\dagger}$ \\
\hline \multicolumn{7}{|l|}{ Eulophidae } \\
\hline Asecodes erxias (Walker) & & & & & $1(33.3)^{\dagger}$ & \\
\hline Diglyphus albiscapus Erdös & & & & $1(3.8)$ & & \\
\hline Diglyphus isaea (Walker) & $23(74.2)^{\ddagger}$ & $1(33.3)^{*}$ & $37(84.1)^{\ddagger}$ & & & \\
\hline Diglyphus minoeus (Walker) & & $1(33.3)^{*}$ & $5(11.4)^{\dagger}$ & $19(73.1)^{\ddagger}$ & $2(66.7)^{\ddagger}$ & $25(75.8)^{\ddagger}$ \\
\hline Hemiptarsenus varicornis (Girault) & $7(22.6)^{\dagger}$ & $1(33.3)^{\ddagger}$ & & & & \\
\hline Neochrysocharis formosa (Westwood) & $1(3.2)$ & & $2(4.5)$ & & & \\
\hline Total number & 31 & 3 & 44 & 26 & 3 & 33 \\
\hline \multicolumn{7}{|l|}{ Leafminer } \\
\hline Liriomyza trifolii (Burgess) & 10 & & & 149 & 1 & \\
\hline Liriomyza sativae Blanchard & 22 & 10 & 5 & & 33 & 1 \\
\hline Chromatomyia horticola (Goureau) & & & 2 & & & \\
\hline Total number & 32 & 10 & 7 & 149 & 34 & 1 \\
\hline
\end{tabular}

For each leafminer species, parasitoid species causing the highest $(\ddagger)$ and second highest $(\dagger)$ percent composition are indicated.

small numbers of leafminers and parasitoids were reared and this was reflected in findings such as only four parasitoid species being collected from both areas and only three parasitoids emerging from two samples of L. sativae.

Our results demonstrated that the dominant and common parasitoids obtained from the three leafminer species differed between fields and/or seasons; however, within the same of the leafminer species tested in field exposure.

\section{DISCUSSION}

Two alien leafminers, L. trifolii and L. sativae, and a native leafminer, $C$. horticola, have become serious pests on vegetables and ornamental crops in Japan. Leafminers have a wide host range, and kidney beans exposed in our surveys had many eggs deposited on them by leafminer species other than the species being tested. However, the results of the exposure experiments were probably unaffected by such contamination, either because the exposure period had finished before eclosion of eggs laid by contaminating leafminer species, or because immature contaminating leafminer larvae were infrequently parasitized. Leafminer parasitoids are not reported to attack host eggs (Konishi, 1998), and immature leafminer larvae are fre- quently used for host-feeding but not oviposition by adults in the family Eulophidae (Sugimoto and Ishii, 1979), which was the dominant parasitoid family in our surveys.

Previous studies demonstrated that D. isaea and D. minoeus were abundant on C. horticola (Takada and Kamijo, 1979; Saito, 2004), while N. formosa was one of the most abundant parasitoid species reared from L. trifolii and L. sativae (Saito et al., 1996; Arakaki and Kinjo, 1998; Tokumaru et al., 2007). These findings may have been influenced by the seasonal conditions during which the recordings were made. Hondo et al. (2006) examined temperature tolerance and net reproductive rate at $15,20,25$ and $30^{\circ} \mathrm{C}$ for several parasitoid species. From their results, the authors suggested that $D$. isaea, D. minoeus, C. pentheus and D. pusztensis are more adapted to low temperatures, and $N$. formosa and Hemiptarsenus varicornis (Girault) are more adapted to high temperatures. In our exposure experiments, the dominant parasitoid species differed in each season: the abundant parasitoid species were $D$. isaea, D. minoeus and $C$. pentheus in spring or fall (cool seasons), and $N$. formosa in summer (hot seasons), except D. pusztensis, which was more abundant in summer. However, $C$. horticola has been shown to be abundant in cooler seasons (Chiba, 1983), while the hosts, L. trifolii and 
L. sativae, were found at high densities during warm and hot seasons (Kobayashi et al., 1992; Tokumaru and Abe, 2001). Thus, optimal temperatures for parasitoid development may account for the dominance of different parasitoid species during the three seasons.

Salvo et al. (2005) demonstrated that resource concentration in cultivated habitats has a beneficial effect on the richness and abundance of leafminer parasitoids. In our surveys, however, total numbers of species and individuals of parasitoids were similar between vegetable gardens and grassland within the same season. $C$. pentheus, D. albiscapus, D. isaea, D. minoeus and $N$. formosa were relatively common in the grassland habitat with poor resources, but in contrast, Asecodes delucchii (Boucek), A. erxias (Walker), Opius sp. and Pnigalio katonis (Ishii) were less frequently recorded from grassland. Different habitat distributions of parasitoid species may be influenced by characteristics such as vegetation structure, temperature preferences, motility for host searching and host range, including non-leafminer hosts. In the fall survey, the numbers of species and individuals of parasitoids were lower than surveys in spring and summer, possibly due to reduced efficiency in hostsearching under low temperatures and a decrease in parasitoid density following a decline of leafminer populations.

As mentioned previously, the distribution of parasitoid species varied between the different field and seasonal conditions; however, within a season and within the same experimental field, the dominant parasitoid species were similar for all leafminer species. The finding suggests that the most common leafminer parasitoid species are polyphagous and have no strong or obvious host preference between L. trifolii, L. sativae or C. horticola. Such polyphagous parasitoids have an important role in the dynamics of invasive leafminers. Murphy and LaSalle (1999) reported that invasive leafminer populations have sometimes been observed to decline naturally a few years after invasion, and the authors hypothesized that this could be due to the action of local natural enemies, particularly polyphagous parasitoids. In Japan, alien $L$. trifolii populations declined naturally in the initial area invaded, Shizuoka, four or five years after being first recorded in 1990 (Saito, 2006).

The results obtained in this survey provide infor- mation for the future management of Liriomyza spp. For example, the parasitoid complex of $C$. horticola may be a useful tool for the biological control of Liriomyza leafminer populations in glasshouses, because the dominant parasitoid species exhibit similar abundance in field tests comparing Liriomyza spp. and C. horticola. Studies are underway on the possible augmentative biological control of $L$. sativae populations by parasitoids that emerge from $C$. horticola when infested garden pea plants are introduced into glasshouse tomato crops attacked by $L$. sativae (Doi et al., 2005; Baeza Larios and Ohno, 2007). This method has the advantage that $C$. horticola very rarely infests tomato crops.

\section{ACKNOWLEDGEMENTS}

We thank Dr. Kazuhiko Konishi (National Agricultural Research Center for Hokkaido Region, Hokkaido, Japan) and Dr. Kazuaki Kamijo (Hokkaido, Japan) for identifying the parasitoids.

\section{REFERENCES}

Arakaki, N. and K. Kinjo (1998) Notes on the parasitoid fauna of the serpentine leafminer Liriomyza trifolii (Burgess) (Diptera: Agromyzidae) in Okinawa, southern Japan. Appl. Entomol. Zool. 33: 577-581.

Baeza Larios, G. L. and K. Ohno (2007) Larval summer diapauses of Chrysocharis pubicornis (Zetterstedt) (Hymenoptera: Eulophidae), a pupal parasitoid of agromyzid leafminers: Sensitive stage for diapauses induction and effects of cool exposure on diapauses termination. Appl. Entomol. Zool. 42: 587-594.

Chiba, T. (1983) Seasonal prevalence of the garden pea leafminer, Phytomyza horticola Goureau (Diptera: Agromyzidae), on spring field pea and the control by application of some insecticides. Ann. Rept. Plant Prot. North Japan 34: 50-52 (in Japanese).

Doi, M., Y. Tagami, S. Kaneko, K. Sugiyama, H. Katayama and T. Saito (2005) Parasitoids of Chromatomyia horticola (Goureau) (Diptera: Agromyzidae) on garden pea in Japan. 2nd Int. Symp. Boil. Cont. Arthropods, Davos, Switzerland, Vol. III, pp. 70-71.

Hondo, T., A. Koike and T. Sugimoto (2006) Comparison of thermal tolerance of seven native species of parasitoids (Hymenoptera: Eulophidae) as biological control agents against Liriomyza trifolii (Diptera: Agromyzidae) in Japan. Appl. Entomol. Zool. 41: 73-82.

Iwasaki, A., K. Kasuga, R. Iwaizumi and M. Sasakawa (2000) A newly recorded pest, Liriomyza sativae Blanchard in Japan. Plant Prot. 54: 12-17 (in Japanese).

Kamijo, K. (1978) Chalcidoid parasites (Hymenoptera) of Agromyzidae in Japan, with description of a new species. Kontyu 46: 455-469.

Kobayashi, H., T. Furuki and S. Ishigami (1992) Occurrence of the legume leafminer, Liriomyza trifolii Burgess, in 
Shizuoka Prefecture. Ann. Rept. Kanto Pl. Prot. Soc. 39: 227-232 (in Japanese).

Konishi, K. (1998) An illustrated key to the Hymenopterous parasitoids of Liriomyza trifolii in Japan. Misc. Publ. Natl. Inst. Agro-Environ. Sci. 22: 27-76 (in Japanese).

Murphy, S. T. and J. LaSalle (1999) Balancing biological control strategies in the IPM of New World invasive Liriomyza leafminers in field vegetable crops. Biocontr. News Info. 20: 91-104.

Oatman, E. R. and G. G. Kennedy (1976) Methomyl induced outbreak of Liriomyza sativae on tomato. J. Econ. Entomol. 69: 667-668.

Ohta, I., A. Kawai and K. Honda (2005) Susceptibility of Liriomyza sativae larvae to commercial insecticides and acaricides and its differences among local populations. Ann. Rept. Kansai Pl. Prot. Soc. 47: 21-24 (in Japanese with English summary).

Parrella, M. P. and C. B. Keil (1984) Insect pest management: The lesson of Liriomyza. Bull. Entomol. Soc. Am. 30: 22-25.

Saito, T. (1993) Occurrence of the leafminer, Liriomyza trifolii (Burgess), and its control in Japan. Agrochem. Japan 62: 1-3.

Saito, T. (2004) Insecticide susceptibility of the leafminer, Chromatomyia horticola (Goureau) (Diptera: Agromyzidae). Appl. Entomol. Zool. 39: 203-208.

Saito, T. (2006) Glasshouse pests and microbial control. Ann. Rept. Plant Prot. North Japan 57: 1-9 (in Japanese).

Saito, T., T. Oishi, F. Ikeda and T. Sawaki (1992) Effect of insecticides on the serpentine leafminer, Liriomyza trifolii (Burgess) (Diptera: Agromyzidae). Jpn. J. Appl. Entomol. Zool. 36: 183-191 (in Japanese with English summary).

Saito, T., F. Ikeda and A. Ozawa (1996) Effect of pesticides on parasitoid complex of serpentine leafminer Liriomyza trifolii (Burgess) in Shizuoka Prefecture. Jpn. J. Appl. Entomol. Zool. 40: 127-133 (in Japanese with English summary).

Salvo, A., M. S. Fenoglio and M. Videla (2005) Parasitism of a leafminer in managed versus natural habitats. Agric. Ecosyst. Environ. 109: 213-220.

Schuster, D. J. and J. K. Price (1985) Impact of insecticides on Lepidopterous larval control and leafminer parasite emergence on tomato. Proc. Fl. State Hort. Soc. 98: $248-251$

Sugimoto, T. and M. Ishii (1979) Monirality of larvae of a ranunculus leaf mining fly, Phytomyza ranunculi (Diptera: Agromyzidae), due to parasitization and hostfeeding by its Eulophid parasite, Chrysocharis pentheus (Hymenoptera: Eulophidae). Appl. Entomol. Zool. 14: 410-418.

Takada, H. and K. Kamijo (1979) Parasite complex of the garden pea leaf-miner, Phytomyza horticola Goureau, in Japan. Kontyu 47: 18-37.

Tokumaru, S. and Y. Abe (2001) Biology of the vegetable leafminer, Liriomyza sativae Blanchard, in Kyoto Prefecture. Plant Prot. 55: 64-66 (in Japanese).

Tokumaru, S., H. Kurita, M. Fukui and Y. Abe (2005) Insecticide susceptibility of Liriomyza sativae, L. trifolii, and L. bryoniae (Diptera: Agromyzidae). Jpn. J. Appl. Entomol Zool. 49: 1-10 (in Japanese with English summary).

Tokumaru, S., Y. Ando, T. Kakeuchi and Y. Abe (2007) Seasonal prevalence of hymenopterous parasitoids of leafminers, Liriomyza sativae Blanchard, L. trifolii (Burgess), and L. bryoniae (Kaltenbach) (Diptera: Agromyzidae) in Kyoto Prefecture. Ann. Rept. Kansai Pl. Prot. Soc. 49: 3-8 (in Japanese with English summary). 